\title{
Thematische Übersicht
}

\section{A. Verwaltungsprozessrecht}

- Bedeutung und Funktion verwaltungsgerichtlicher Kontrolle (§ 1 Rn. $7 \mathrm{ff}$.

- Die Eröffnung des Verwaltungsrechtswegs (§1 Rn. 162ff.)

- Die Klage- und Antragsarten der VwGO (Einführung und Überblick: $§ 1$ Rn. 222ff.)

- Die Anfechtungsklage (Prüfungsschema: 22 Rn. 1; Statthaftigkeit: $§ 2$ Rn. 2ff.; Weitere Zulässigkeitsvoraussetzungen: § 2 Rn. 280 ff.; Begründetheit: $\S 2$ Rn. $506 \mathrm{ff}$.)

- Die Verpflichtungsklage (Prüfungsschema: §3 Rn. 1; Statthaftigkeit: §3 Rn. 2 ff.; Weitere Zulässigkeitsvoraussetzungen: $§ 3$ Rn. 27 ff.; Begründetheit: $\S 3 \mathrm{Rn} .46 \mathrm{ff}$.)

- Die Fortsetzungsfeststellungsklage (Prüfungsschema: §4 Rn. 1; Statthaftigkeit: § 4 Rn. 2ff.; Weitere Zulässigkeitsvoraussetzungen: § 4 Rn. 32ff.; Begründetheit: $\S 4$ Rn. 59 ff.)

- Die allgemeine Leistungsklage (Prüfungsschema: $\S 5$ Rn. 1; Statthaftigkeit: § 5 Rn. 2ff.; Weitere Zulässigkeitsvoraussetzungen: §5 Rn. 30 ff.; Begründetheit: $\S 5$ Rn. $48 \mathrm{ff}$.)

- Die Feststellungsklage (Prüfungsschema: $\S 6$ Rn. 1; Statthaftigkeit: $\S 6$ Rn. 2ff.; Weitere Zulässigkeitsvoraussetzungen: $§ 6$ Rn. 77 ff.; Begründetheit: $\S 6$ Rn. 102ff.)

- Die verwaltungsgerichtliche Normenkontrolle (Prüfungsschema: §7 Rn. 1; Statthaftigkeit: $\S 7$ Rn. 2 ff.; Weitere Zulässigkeitsvoraussetzungen: $\S 7$ Rn. 33 ff.; Begründetheit: $\S 7$ Rn. 60 ff.)

- Der Antrag nach $\S 80$ V VwGO (Prüfungsschema: § 8 Rn. 1; Statthaftigkeit: $\S 8$ Rn. 2ff.; Weitere Zulässigkeitsvoraussetzungen: §8 Rn. $29 \mathrm{ff}$.; Begründetheit: § $8 \mathrm{Rn} .49 \mathrm{ff}$.)

- Der Antrag nach $\S \S 80,80 a$ VwGO (Prüfungsschema: $\S 9$ Rn. 1; Statthaftigkeit: $\S 9$ Rn. 2ff.; Weitere Zulässigkeitsvoraussetzungen: $§ 9$ Rn. 33 ff.; Begründetheit: $\S 9$ Rn. $46 \mathrm{ff}$.)

- Der Antrag nach $\S 123$ VwGO (Prüfungsschema: 110 Rn. 1; Statthaftigkeit: $\S 10$ Rn. 2ff.; Weitere Zulässigkeitsvoraussetzungen: $\S 10$ Rn. 10 ff.; Begründetheit: $\S 10 \mathrm{Rn} .26 \mathrm{ff}$.) 


\section{B. Allgemeines Verwaltungsrecht}

- Die Handlungsformen der Verwaltung (Einführung und Überblick: §1 Rn. 222ff.)

- Der Verwaltungsakt (Begriff: §2 Rn. $38 \mathrm{ff.;}$ Wirksamkeit: §2 Rn. $98 \mathrm{ff.;}$ Rechtmäßigkeit: § 2 Rn. 553 ff.; Rücknahme und Widerruf: § 2 Rn. 836 ff.; Nebenbestimmungen: $\S 2$ Rn. $204 \mathrm{ff}$. und 1388ff.)

- Der öffentlich-rechtliche Vertrag (§5 Rn. $65 \mathrm{ff}$.)

- Der Realakt (Begriff: § 5 Rn. 6 ff.; Rechtmäßigkeit: § 6 Rn. 108 ff.)

- Untergesetzliche Rechtsnormen (Rechtsverordnung: $§ 7$ Rn. 23; Satzung: $\S 7$ Rn. 24; Verwaltungsvorschrift: § 7 Rn. 25; Rechtmäßigkeit einer Norm: $\S 7$ Rn. $72 \mathrm{ff}$.)

- Plan und Planung (§ 1 Rn. 242)

- Verwaltungsprivatrechtliches Handeln (§1 Rn. 243)

- Die Organisation der Verwaltung (§ 2 Rn. 580 ff.)

- Das Verwaltungsverfahren i.S.d. VwVfG (§ 2 Rn. 621 ff.)

- Grundsatz der Gesetzmäßigkeit der Verwaltung (§ 2 Rn. 554 ff.)

- Ermessen und unbestimmter Rechtsbegriff (§ 2 Rn. $719 \mathrm{ff}$.)

- Das subjektive öffentliche Recht (§ 2 Rn. 828)

- Verwaltungsvollstreckungsrecht (Einführung: § 2 Rn. 1293 ff.)

- Der öffentlich-rechtliche Abwehr- und Unterlassungsanspruch (§ 5 Rn. $65 \mathrm{ff}$.)

- Recht der öffentlichen Ersatzleistungen / Staatshaftungsrecht (Struktur des Staatshaftungsrechts ( $\S 5$ Rn. 153ff.); Der Folgenbeseitigungsanspruch ( 5 Rn. 169 ff.; zum Vollzugsfolgenbeseitigungsanspruch $\S 2$ Rn. 1387); Der allgemeine öffentlich-rechtliche Erstattungsanspruch (§ 5 Rn. 189ff.); Ausgleich für Inhalts- und Schrankenbestimmungen ( $\$ 5 \mathrm{Rn}$. 212ff.); Unrechtshaftung (§ $11 \mathrm{Rn} .1 \mathrm{ff}$.$) ; Sonderopferentschädigung (§ 11 \mathrm{Rn} .61 \mathrm{ff}$.

\section{Besonderes Verwaltungsrecht}

- Einführung in das Polizei- und Ordnungsrecht (§ 2 Rn. 1008 ff.)

- Einführung in das Versammlungsrecht (§ 2 Rn. $1141 \mathrm{ff}$.)

- Einführung in das Baurecht ( $\$ 2$ Rn. $1227 \mathrm{ff}$.)

- Einführung in das Kommunalrecht (§ 2 Rn. 1255 ff.) 